\title{
SCANNING ELECTRON MICROSCOPY AND X-RAY SPECTRAL MICROANALYSIS IN STUDYING DENTAL TISSUE RESISTANCE
}

\section{M.P. Porfyriadis' ${ }^{1}$ D.A. Domenyuk ${ }^{1}$, A.G. Arutyunova ${ }^{2}$, S.V. Dmitrienko ${ }^{3}$}

\author{
${ }^{1}$ Department of general practice dentistry and child dentistry, Stavropol \\ State Medical University, Ministry of Healthcare of Russian Federation, 310, \\ Mira Street, Stavropol, Russia 355017.E-mail:domenyukda@mail.ru, \\ tel: +7918870 1205 \\ ${ }^{2}$ Department of Pediatric Dentistry, Orthodontics and Maxillofacial \\ Surgery, Kuban State Medical University, Ministry of Healthcare of Russian \\ Federation, M. Sedina str., 4, Krasnodar, Russia, 350063. \\ E-mail: kaf-detstom@yandex.ru, tel: +78612680210 \\ ${ }^{3}$ Department of Dentistry, Pyatigorsk Medical-Pharmaceutical Institute \\ (Branch of Volgograd State Medical University, Ministry of Healthcare, \\ Russian Federation, 11, pr. Kalinina, Pyatigorsk-32, Stavropol Region, \\ Russia 357532.E-mail: s.v.dmitrienko@pmedpharm.ru, \\ tel: +78793324474
}

\section{INTRODUCTION}

The results of the multinational pilot research project European Oral Health Indicators (EGOHID-2005 system) for 2013-2018 revealed that the lowest level of hard tissues mineralization in permanent teeth was observed in the first years after their eruption. Thus, in the key age categories for 12-yearold children, the prevalence of caries was 81.1-100\% with an intensity of 3.51-5.03, while for the 15-yearolds the numbers amounted to $84.3-100 \%$ and 4.17-6.27, respectively [1-7].

Experts studying caries believe that the pattern of increase in the prevalence and intensity of carious lesions in permanent teeth in children through 6 to 15 years of age is due to the following factors: diet imbalance; physiological hypomineralization of the teeth hard tissues due to incomplete enamel maturation; increased pathology in pregnant women; chronic maternal diseases leading to fetal hypoxia; use of medication; genetic susceptibility to caries; environmental issues; reduced overall resistance in children [8-14]. One of the negative factors is premature transfer to formula feeding, which entails overstrain in adjustment mechanisms and immunity. Failure of the physiological systems in case of changed type of feeding leads to a rapid increase in weight $\&$ height parameters with the redistribution of calcium-phosphorus ratio, which is not in favor of hard tooth tissues. An important role also belongs to physical development acceleration, which leads to earlier eruption of not milk teeth only, yet also of permanent teeth [15-21].

\author{
Article history: \\ Received 8 February 2019 \\ Received in revised form 12 March 2019 \\ Accepted 15 March 2019
}

ABSTRACT - AIm. Potential use of scanning electron microscopy with X-ray spectral microanalysis to determine the structural, functional and acid resistance of tooth enamel through mineralization stages.

MATERIALS AND METHODS. A VEGA II LMU highresolution scanning electron microscope with an INCA Energy 350XT X-ray microanalyzer, were used to identify the degree of packing, size, and shape of enamel prisms and interprismatic intervals, as well as the content of chemical elements in the upper layer of permanent teeth enamel. Structural, functional and acid resistance of enamel was studied using the enamel resistance test (V.R. Okushko, 1984). The material used included 47 premolars (removed for orthodontic reasons) with no sign of carious lesions in children belonging to the age group of 11-16 with a mineralization period of 6-60 months from the time of eruption.

RESULTS. The results of X-ray spectral microanalysis regarding the chemical elements content in weight percent, revealed that through the maturation (mineralization) stages, the surface enamel layer featured a significant trend towards increasing the $\mathrm{Ca}, \mathrm{P}$, and $\mathrm{F}$ concentration, as well as $\mathrm{Ca} / \mathrm{P}$ ratio, along with a decrease in the level of $\mathrm{C}, \mathrm{Na}, \mathrm{O}$. An investigation into children undergoing the early stages of physiological maturation revealed that tooth enamel had a hypomineralized structure of the hydroxyapatites crystalline grid a with disturbed spatial orientation and boundaries accuracy, changed organic matrix depth, increased shell size and polymorphisms in the enamel prisms structure along with a reduced density of their packing. The combination of these signs is indicative of incomplete development of prismatic enamel structures with an unbalanced ratio of the mineral component and the organic matrix.

Conclusion. The obtained results demonstrate potential use of high-resolution electron microscopy with X-ray spectral microanalysis to study dental hard tissues. Development and introduction of personalized approaches to caries prevention based on selective usage of remineralizing drugs and vitamin-mineral complexes, would improve resistance to caries through all stages of physiological maturation.

KEYW ORDS - scanning electron microscopy, X-ray spectral microanalysis, caries resistance, enamel mineralization, enamel chemical composition.

Most specialists claim that the central role in caries development belongs to the local situation in the oral cavity. Lack of proper hygienic care, for instance, as well as increased microbial contamination, excessive 
development of dental plaque deposits, hypo-salivation, periodontal inflammatory issues, and the development of multiple retention spots act as conditions facilitating rapid caries progress [22-26].

Some researchers, however, question the key role of the previously identified factors, because in people featuring high resistance to caries, these issues do not lead to carious lesion. In their opinion, caries resistance is due to morphological features of the enamel structure, the structure specifics, the teeth shape and microrelief, and the presence and size of the gaps between the teeth [27-34].

In children, during eruption or soon after it is complete, poorly mineralized hard tooth tissues have no time to be saturated with micro- and macroelements, and are in the phase of structural and functional immaturity being most susceptible to intensive saturation with mineral components. The enamel of immature teeth reveals high variability of morphological structures. This morphology features immature enamel microroughness, where depressions, niches, micropores, and areas of minor packing density of crystalline structures are combined with wide interprismatic intervals and unclear boundaries of enamel prisms. An erupted tooth enamel has a volume of micropores reaching $6 \%$, while in mature enamel this index will not exceed $0.2 \%$. In immature enamel, apatites are mainly represented by the hydroxyapatites that are least resistant to dental plaque acids [35-41].

Experts state that the chemical composition specifics, incomplete mineralization and the specific morphology combined with the microroughness of immature enamel in the children lay the ground for a cariogenic situation entailing high risk of carious lesions due to significant enamel solubility, low acid resistance, a tendency towards focal demineralization, and poor resistance to the aggressive action of cariogenic factors [42-47]. Despite the significant amount of published studies focusing on the permanent teeth enamel caries-resistance at the maturation stages, given the modern clinical and diagnostic approaches, the available data on the chemical composition and microstructure of the surface during intensive tertiary mineralization is scarce and isolated, which determined the purpose of this study.

To investigate potential use of scanning electron microscopy and X-ray spectral microanalysis in identifying the structural $\&$ functional, as well as acid resistance of tooth enamel through the mineralization stages.

\section{MATERIALS AND METHODS}

On the premises of Department of Pediatric Dentistry, Orthodontics and Oral and Maxillofacial Surgery (Kuban State Medical University) we carried out an evaluation of the dental status in 38 children aged 11-16 undergoing orthodontic treatment and diagnosed with Class (K07) "Oral and maxillofacial anomalies [including bite anomalies]", subclass (K07.3) "Anomalies of the teeth: crowded teeth" (ICD-10).

The criteria for the inclusion in the study were: I-II health groups (by Yu.E. Veltischev, 1994); a good level of dental health: DMF index below 2.6; oral hygiene index (OHI) (Yu.A. Fedorov, V.V. Volodkina, 1970) below 2.0; OHI-S (Green, Vermillion, 1964 below 1.6; Type I-II microcrystallization of oral fluid; teeth (premolars) recommended to be removed for orthodontic reasons with no signs of carious lesions.

At the first stage of the work, the assessment of the structural \& functional and acid resistance of the enamel on the premolars to be removed for orthodontic reasons, was performed using the enamel resistance test (ERT-test, V.R. Okushko, L.I. Kosareva, 1984). The diagnostics of enamel focal demineralization in the teeth to be removed for orthodontic reasons was performed through the method of vital staining $(A x-$ amit L.A., 1978) and Caries Indicator (Omega Dent, Russia). The enamel staining intensity was evaluated with a colorimetric scale featuring shades of blue from slightly bluish to dark blue.

At the second stage, atraumatic removal of teeth that erupted simultaneously was performed in order to save the surface layer of enamel in the maximum possible way. The teeth ( 47 premolars of children aged 11-16, yet no later than six months after the eruption) with no carious signs were removed for orthodontic reasons. All the extracted teeth were divided into three groups. Group 1 included 13 teeth extracted from children aged 11-12 (hard tissues mineralization term 6-12 months from eruption). Group 2 included 19 teeth removed from children aged 13-14 (hard tissues mineralization term 13-36 months from eruption). Group 3 included 15 teeth that were removed from adolescents, $15-16$ years old (hard tissues mineralization term 37-60 months from eruption). Immediately after extraction, the teeth were immersed in a $2 \%$ Monochloramine $\mathrm{B}$ aqueous solution for 30 minutes with further careful ultrasound treatment to remove the remaining periodontal ligaments, soft tissues, and dental plaque. Then the teeth roots were separated at the level of the enamel-cement joint point, while the coronary segments were further polished with brushes and the Cleanic (Kerr) universal polishing paste. To prevent artifacts typical of chemical fixation of sam- 
ples, as well as to inhibit biochemical reactions in the enamel samples, they were stored in a solution of artificial saliva (T. Fusayama, 1975) in a glass container with a ground-in lid placed in a thermostat $(\mathrm{pH}=7.0 \pm 0.2$; $\mathrm{t}=10.0^{\circ} \mathrm{C}$ ).

The third stage, including the study of the chemical composition and microstructure of the enamel samples surface, was carried out at the Department of Nanomaterial Technology, Engineering Institute, North-Caucasus Federal University. While preparing the teeth for the study, the conventional method was employed: with water cooling and a $0.2 \mathrm{~mm}$ diamond disc, enamel was cut at the equator area from the oral and vestibular surfaces of the crowns, to be further treated with ultrasound, degreased, and subjected to vacuum. The chemical composition and microstructure of the enamel surface layer samples was studied in a VEGA II LMU scanning electron microscope («Tescan») with the INCA Energy 350XT X-ray microanalysis system (Oxford Instruments Analytical, England). The samples surfaces were fixed on a glass slide and then sprayed with carbon $(\mathrm{h}=12-15 \mathrm{~nm})$ in a VUP-5 vacuum unit for electrical conductivity thus ensuring optimal conditions for microscopy (Fig. 1).

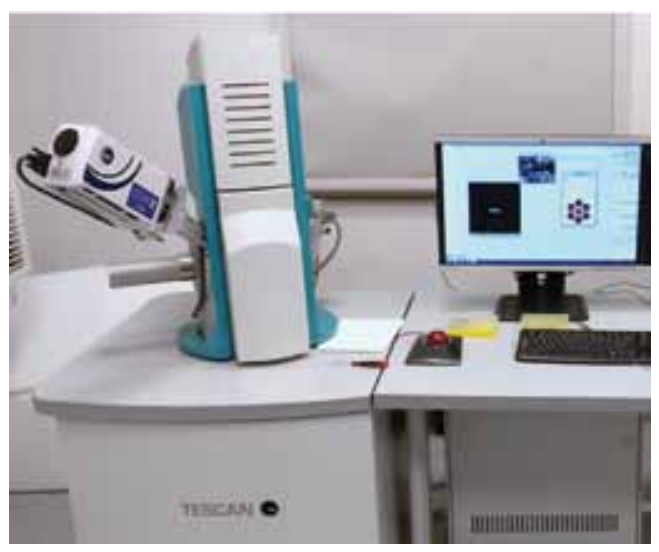

Fig. 1. Scanning electron microscope VEGA II LMU ("Tescan") with an Oxford Instruments INCA Energy 350XT X-ray energy dispersive microanalysis system

The statistical processing was performed using the statistical software packages Excel and Statistica 10.0. To assess the differences in categorical variables in the groups, the exact Fisher's or $\chi^{2}$ method was used. When describing quantitative indicators, the mean value $(\mathrm{M})$ and standard deviation $(\mathrm{m})$ were used. To analyze the significance of the differences among the compared groups, the Kruskal-Wallis criterion was used. The critical level of significance when testing the statistical hypotheses was taken as 0.05 .

\section{RESULTS AND DISCUSSION}

Table 1 shows the status of structural \& functional, and acid resistance of tooth enamel at the equator area through various mineralization stages.

Analysis of the clinical and diagnostic data in groups involved in the study shows that an increase in the time of hard tooth tissues mineralization came along with an increase in the structural and functional, as well as acid resistance of the tooth enamel, which is also accompanied with a decrease in the enamel staining intensity. We suppose that statistically significant dynamics of improvement in structural, functional and acid resistance (reduced enamel permeability), as well as prolonged enamel maturation period are due to an increased activity in the fluoroapatite development mechanisms, obvious prevalence of morphological completeness (structural maturity), and consistent salivary homeostasis along with proper self-regulation of calcium-phosphorus metabolism in the oral cavity. Table 2 shows the change dynamics in the content of chemical elements in the surface layer of permanent teeth enamel through mineralization.

The study of the chemical composition of the permanent teeth enamel surface through various mineralization stages reveals that the most common elements in the enamel are oxygen $(\mathrm{O})$, calcium $(\mathrm{Ca})$, phosphorus $(\mathrm{P})$, and carbon $(\mathrm{C})$. The remaining elements, whose mass content exceeds $0.01 \%$ are nitrogen $(\mathrm{N})$, sodium $(\mathrm{Na})$, chlorine $(\mathrm{Cl})$, magnesium $(\mathrm{Mg})$, fluorine $(\mathrm{F})$, and silicon $(\mathrm{Si})$. Evaluation of the chemical composition of the permanent tooth surface enamel suggests that the maturation stages (mineralization) show a prominent tendency towards an increase in the concentration of $\mathrm{Ca}, \mathrm{P}, \mathrm{F}, \mathrm{Ca} / \mathrm{P}$ ratio along with reducing levels of $\mathrm{C}, \mathrm{Na}$, and $\mathrm{O}$. In Group 2, the increase in the chemical elements content in the enamel surface layer was: $\mathrm{Ca}-7.97 \pm 0.46 \%, \mathrm{P}-2.17 \pm 0.21 \%, \mathrm{~F}-$ $33.33 \pm 2.18 \%$; in Group 3: Ca $-14.04 \pm 0.93 \%, \mathrm{P}-$ $4.75 \pm 0.34 \%, \mathrm{~F}-55.56 \pm 4.08 \%$.

In our opinion, higher resistance and mineralization through an increase in the macroand microelements that are part of fluorapatite $\left[\left[\mathrm{Ca}_{10}\left(\mathrm{PO}_{4}\right) 6 \mathrm{~F}_{2}\right]\right.$, hydroxyapatite $\left[\mathrm{Ca}_{10}\left(\mathrm{PO}_{4}\right) 6(\mathrm{OH})_{2}\right]$, chlorapatite $\left[\mathrm{Ca}_{10}\left(\mathrm{PO}_{4}\right) 6 \mathrm{Cl}_{2}\right]$, carbonapatite $\left[\mathrm{Ca}_{10}\left(\mathrm{PO}_{4}\right)_{5} \mathrm{CO}_{3}(\mathrm{OH})_{2}\right]$ during enamel maturation is due to the following factors:

1. Intracrystalline ion exchange reaction in the hydroxyapatite grid with the introduction of ions $\left(\mathrm{Ca}^{2+}, \mathrm{PO}_{4}^{3-}, \mathrm{CO}_{3}^{2-}, \mathrm{F}^{2-}\right)$ from the crystals surface deep into the ion grid.

2. Possible displacing of isomorphic ions $\left(\mathrm{Ca}^{2+}\right.$ antagonists) in the crystalline grid of hydroxyapatite by $\mathrm{Ca}^{2+}$ or replacing vacant sites with calcium due to an increase in the $\mathrm{Ca}^{2+}$ concentration in the oral fluid. 
Table 1. Structural \& functional resistance and acid resistance of tooth enamel in the equatorial region at various stages of mineralization, $(M \pm m)$

\begin{tabular}{l|l|l|l}
\hline \multirow{2}{*}{ Parameters } & \multicolumn{3}{|l}{ Terms of mineralization of hard tissues of teeth from the moment of eruption } \\
\cline { 2 - 4 } & $6-12$ months & $13-36$ months & $37-60$ months \\
\hline ERT-test, \% & $27,19 \pm 1,04$ & $24,72 \pm 1,38^{*}$ & $18,63 \pm 0,96^{*}$ \\
\hline Enamel staining intensity, points & $2,58 \pm 0,16$ & $2,31 \pm 0,19^{*}$ & $1,67 \pm 0,12^{*}$ \\
\hline
\end{tabular}

Note: ${ }^{*}$ - statistically significant in relation to the indicators of the first group, $(p \leq 0.05)$.

Table 2. The concentration of chemical elements in the surface layer of enamel permanent teeth during the stages of tertiary mineralization, (in mass \%), $(M \pm m)$

\begin{tabular}{l|l|l|l}
\hline \multirow{2}{*}{ Chemical element } & \multicolumn{2}{l}{ Terms of mineralization of hard tissues of teeth from the moment of eruption } \\
\cline { 2 - 4 } & $6-12$ months & $13-36$ months & $37-60$ months \\
\hline $\mathrm{Ca}$ & $21,08 \pm 0,93$ & $22,76 \pm 1,12^{*}$ & $24,04 \pm 0,85^{*}$ \\
\hline $\mathrm{P}$ & $14,74 \pm 0,39$ & $15,06 \pm 0,63^{*}$ & $15,44 \pm 0,49^{*}$ \\
\hline $\mathrm{Ca} / \mathrm{P}$ & $1,43 \pm 0,07$ & $1,51 \pm 0,05^{*}$ & $1,56 \pm 0,08^{*}$ \\
\hline $\mathrm{C}$ & $8,03 \pm 0,56$ & $7,68 \pm 0,39^{*}$ & $7,04 \pm 0,41^{*}$ \\
\hline $\mathrm{O}$ & $53,66 \pm 5,17$ & $51,96 \pm 4,77^{*}$ & $51,07 \pm 4,93^{*}$ \\
\hline $\mathrm{F}$ & $0,09 \pm 0,02$ & $0,12 \pm 0,03^{*}$ & $0,14 \pm 0,01^{*}$ \\
\hline $\mathrm{Mg}$ & $0,24 \pm 0,03$ & $0,21 \pm 0,05^{*}$ & $0,23 \pm 0,04^{*}$ \\
\hline $\mathrm{Na}$ & $0,59 \pm 0,09$ & $0,57 \pm 0,04^{*}$ & $0,51 \pm 0,03^{*}$ \\
\hline $\mathrm{Cl}$ & $0,43 \pm 0,06$ & $0,47 \pm 0,03^{*}$ & $0,42 \pm 0,05^{*}$ \\
\hline $\mathrm{Si}$ & $0,03 \pm 0,006$ & $0,03 \pm 0,008^{*}$ & $0,04 \pm 0,009^{*}$ \\
\hline $\mathrm{N}$ & $1,11 \pm 0,17$ & $1,14 \pm 0,11^{*}$ & $1,07 \pm 0,16^{*}$ \\
\hline
\end{tabular}

Note: ${ }^{*}$ - statistically significant in relation to the indicators of the first group, $(p \leq 0.05)$.

3. Reaction of isomorphic substitution of $\mathrm{HO}$ groups for $\mathrm{F}^{-}$in the hydroxyapatite ionic grid, with the development of hydroxyfluoroapatites or fluorapatites (fluoridation), which has a protective effect. This helps increase the hydroxyapatite crystals size due to increased precipitation from the oral fluid, as well as increases the enamel acid resistance.

4. Considerable total surface of the apatites in mineralized tissues allows them to absorb not charged particles alone, yet also electrically neutral molecules.

5. The enamel surface layer, as a hyper-mineralized area, features a maximum concentration level of nearly all mineral elements, especially calcium, phosphorus, fluorine with a gradual decrease in the content following the direction from the surface to the enamel-dentin boundary.

6. Fluoride maximum concentration in the enamel surface layer is considered a key caries-resistant factor, as well as an inhibitor of pathogenic (opportunistic) oral cavity microflora. The fluorine content in the deeper enamel layers decreases, yet the $\mathrm{Ca} / \mathrm{P}$ ratio increases since at the approach to the dentin-enamel border, the number of carbonate-apatites increases. Rise in the molar $\mathrm{Ca} / \mathrm{P}$ ratio in the enamel surface layer (patients of Group $2-5.59 \pm 0.37 \%$, patients of Group $3-9.09 \pm 0.62 \%)$ with an increase in the enamel maturation (calcification) term up to the maximum level (2.0) in adolescents aged 15-16, indicates almost complete mineralization, low intensity of demineralizing processes, and absence of prominent ionic substitutions for mineral components.

An increase in the hard tooth tissues maturation (mineralization) time has been observed to come along with a decrease in the levels of oxygen, carbon and other light elements shaping the organic basis of enamel, as well as chlorine and sodium. The decrease in the chemical elements concentration in the enamel surface layer in Group 2 was: $\mathrm{O}-3.17 \pm 0.19 \%$, C $-4.36 \pm 0.27 \%, \mathrm{Na}-3.39 \pm 0.24 \%$; in Group 3: $\mathrm{O}-$ $4.83 \pm 0.22 \%, \mathrm{C}-12.33 \pm 0.74 \%, \mathrm{Na}-13.56 \pm 0.86 \%$. The variability of other chemical elements by mass 
ratio (magnesium, chlorine, silicon, nitrogen) had no statistically significant differences.

The connection between morphological features and chemical composition of the permanent teeth enamel surface layer through various mineralization stages has been confirmed with the data from scanning electron microscopy. The enamel surface in teeth with a mineralization period of 6-12 months reveals clearly visible perikymata (Retzius striae). Perikymata are areas of extremely low mineralization that are transverse to enamel prisms and have a thickness of 200-400 nm. Perikymata border shows enamel prisms outing, while the enamel surface itself is unclear (dim) and not smooth featuring a high degree of roughness. Microscopic examination of the dental enamel in children through early maturation revealed the following morphological features - hypomineralized structure of hydroxyapatites crystalline grid with a disturbed spatial orientation (chaotic arrangement) and clear boundaries; changing depth of the organic matrix; increased shell size and polymorphisms in the enamel prisms structure (pentagon and hexagon); reduced size of enamel prisms in vertical and horizontal planes; a decrease in the enamel prisms packing density per volume unit (increased interprismatic distance and the height of the interprismatic intervals). The total of these morphological features indicates an incomplete prismatic enamel structure due to disturbed relations between the mineral component and the organic matrix, a low level of maturation (mineralization) of its surface, deficient protective layer on the surface, significant permeability degree of immature enamel, as well as the presence of extra retention spots for microflora. Systematizing the obtained data regarding the surface morphology, we can speak of low caries resistance and acid resistance of immature enamel with a high risk of susceptibility to caries in children aged 11-12 (Fig. 2).

In Group 2 (mineralization term of 13-36 months) perikymata on the tooth enamel surface were less prominent, while there was a tendency to their smoothing, whereas the perikymata surface itself was smooth and homogeneous. Compared to patients in Group 1, the number of enamel prism outings (open, closed cup-shaped depressions - craters) not only within the perikymata, yet also at their borders, was significantly reduced, while the craters on the enamel surface were obviously deeper and much smaller in the area. The enamel surface featured some shine, also becoming smoother and more uniform. The appearance of scratches, grooves and microcracks, which surround enamel prism groups, while creating a honeycombshaped structure, indicates an insufficient degree of mineralization. Electron microscopy of tooth enamel allows identifying the following morphological features: relative orderliness of the hydroxyapatite crystals spatial orientation; prevalence of the enamel prisms close to the normal (standard) size in the vertical and horizontal planes, with an arcuate shape and clear boundaries; the averaged amount of enamel prisms per volume unit (packing density); a slight increase in the height of interprismatic intervals and distances. In our opinion, the mineral layer deposited on the enamel surface inhibits full performance of the protective function due to insufficient calcification (mineralization). Visualization of the available morphological data shows that children aged 13-14, if compared with children aged 11-12, feature better caries and acid resistance of enamel along with reduced enamel caries susceptibility (Fig. 3).

Patients of Group 3 (mineralization term of 37-60 months) featured enamel surface with a significantly lower number and area of the open cupshaped depressions (craters), if compared with similar indicators in Groups 2 and 3. The outer surface of the enamel, as a dense, amorphous, transparent structure, features the highest homogeneity and specific shine. Electron microscopy of child tooth enamel at the final stages of its maturation revealed the following qualitative morphological features: a stable, spatially oriented microstructure represented with ordered hexa- and heptagonal arcuate types of enamel prisms that have clearly cut boundaries; proper location of the organic matrix in depth; enamel prism size corresponding to the normal (standard) ones in vertical and horizontal planes; high packing density of enamel prisms per volume unit (minimal interprismatic distance and height of interprismatic intervals). The high-endurance surface layer separates the end surfaces of enamel prisms thus ensuring isolation of their contact surfaces from the aggressive effect of oral fluid, and preventing antagonists from abrading hard tissues. From our point of view, adolescents aged 15-16, if compared to younger children, due to the conditions facilitating high-grade mineralization, have a significantly lower total component (share) of organic matter, while enamel maturation (calcification) is almost complete. The combination of visual morphological signs pointing at a significant increase in the enamel surface mineralization in Group 3 (compared with patients in Groups 1 and 2) indicates a sufficient level of caries and acid resistance with minimal caries susceptibility of the enamel (Fig. 4).

Analysis of the obtained results demonstrates the feasibility of employing the scanning electron microscopy method with X-ray spectral microanalysis to identify the hypomineralization of tooth enamel as a condition promoting caries. 

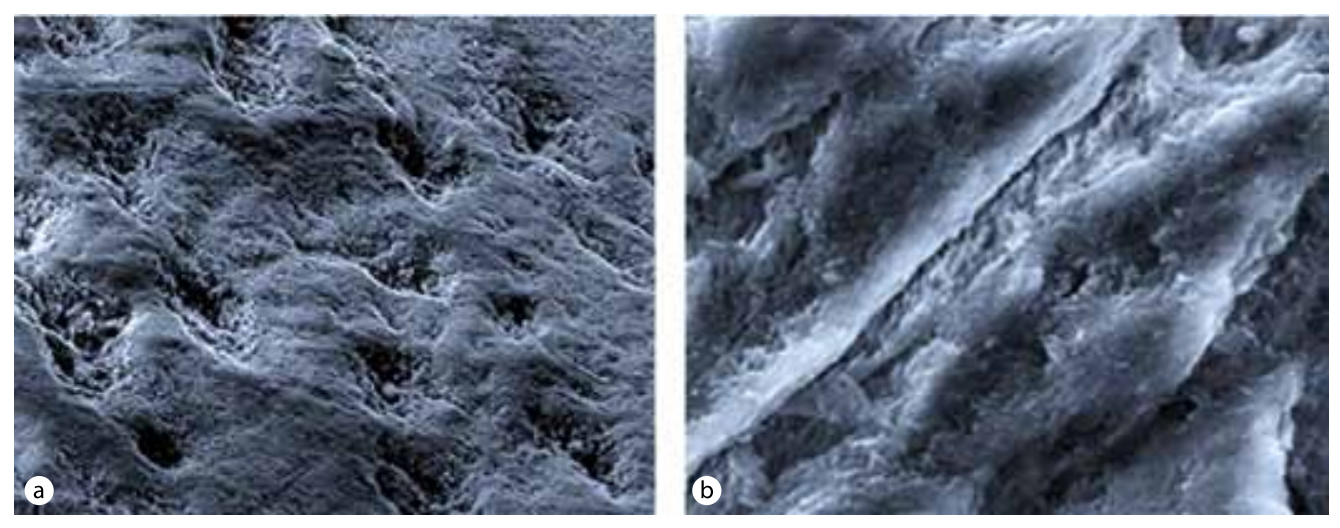

Fig. 2. Scanning electron microscopy of the enamel surface of a permanent tooth with a mineralization period of $6-12$ months.

The magnification $\times 10000(a)$, $\times 30000(b)$

Fig. 3. Scanning electron microscopy of the enamel surface of a permanent tooth with a mineralization period $13-36$ months. The magnification $\times 10000(a), \times 30000(b)$

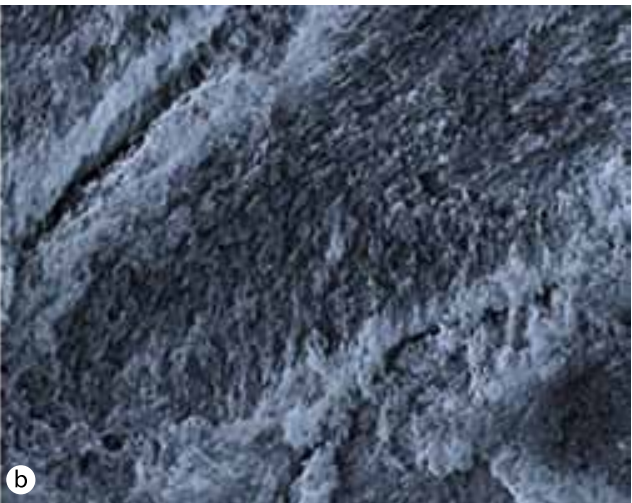

Fig. 4. Scanning electron microscopy of the enamel surface of a permanent tooth with a mineralization period 37-60 months. The magnification $\times 10000(a), \times 30000(b)$

\section{CONCLUSIONS}

1. Studying the morphology and chemical composition of the tooth enamel surface layer employing scanning electron microscopy with an energy dispersive microanalysis system allows obtaining a proper image of the changes typical of various enamel maturation stages. High resolution with possible ratio identification for organic and inorganic components of enamel, allows spotting foci of insufficient tertiary mineralization, which cannot be diagnosed with the available clinical methods (ERT-test, vital staining method).

2. The results of electron probe X-ray spectral microanalysis for the concentration of elements in the mass share indicate that the stages of enamel surface layer maturation reveal a steady trend towards an increase in the content of $\mathrm{Ca}, \mathrm{P}, \mathrm{F}$, as well as $\mathrm{Ca} / \mathrm{P}$ ratio, with a decrease in $\mathrm{C}, \mathrm{Na}$, and $\mathrm{O}$.

3. Tooth enamel in children through the early stages of physiological maturation reveal the following 
morphological features: hypomineralized structure of hydroxyapatites crystalline grid with a disturbed spatial orientation and clear boundaries; changing depth of the organic matrix; increased shell size and polymorphisms in the enamel prisms structure; reduced size of enamel prisms in vertical and horizontal planes; a decrease in the enamel prisms packing density. The combination of morphological features in children belonging to the age group of 11-12 year-olds indicates low caries and acid resistance with high caries susceptibility in immature enamel, which lays the ground for cariogenic situations.

4. The specifics of the macro- and microelement composition, which determines the nature of pathological changes in the hypomineralization center, can be well used for the development and implementation of caries preventive (individual, professional) programs for children. Reasonable introduction of remineralizing and fluorine-containing drugs as well as vitamin-mineral combinations will help stabilize demineralization, establish conditions for saturation of the oral fluid with macro- and microelements, increase caries and acid resistance at the molecular, tissue, organ and system levels, and will also help improve the enamel permeability.

\section{REFERENCES}

1. BaZikov I.A., Domenyuk D.A., Zelensky V.A. Semiquantitative evaluation of caries microflora in patients with dental and alveolar abnormalities and different severity of morphofunctional disturbances. Medical Bulletin of the North Caucasus. 2015; T. 10; 3(39): 238-241. (In Russ., English abstract). DOI: $10.14300 /$ mnnc.2015.10055.

2. Domenyuk D.A., Davydov B.N., Zelensky V.A., KaRSLIEVA A.G. System analysis of risk factors for developing caries in children with dentoalveolar anomalies. Part II. Pediatric Dentistry and Prophylaxis. 2014; Vol. 13; 4 (51): 51-60. (In Russ.)

3. Domenyuk D.A., Davydov B.N., Zelensky V.A., KARSLIEVA A.G. Optimizing the diagnosis of dental caries in patients with dental-anomalies based on the identification of prognostic factors (Part I). Institute of Dentistry. 2014; 3 (64): 37-39. (In Russ.).

4. Davydov B.N., DomenYuk D.A., Bykov I.M., IVCHENKo L.G., DMITRIENKo S.V. Modern possibilities of clinical, laboratory, X-ray studies in preclinical diagnosis and prediction of the risk of developing periodontal diseases in children with diabetes mellitus type one. Part I. Periodontology. 2018; Vol. XXIV; 3-24 (88): 4-11. (In Russ.). DOI: 10.25636/ PMP.1.2018.3.1.

5. Domenyuk D.A., Davydov B.N., Gilmiyarova F.N., IVCHENKo L.G., VEDESHINA E.G. Diagnostic and prognostic value of crystalline structures of the oral fluid in children with anomalies of occlusion. Pediatric Dentistry and Prophylaxis. 2017; Tom XXI; 2(61): 9-16. (In Russ.).

6. Domenyuk D.A., DAVYdov B.N., Vedeshina E.G., DMitrienko S.V. Perfection of diagnostic methods of dentoalveolar anomalies by results of studying functional shifts in the system of oral homeostasis (Part II). The Dental Institute. 2016; 72(3): 58-61. (In Russ.).

7. Bykov I.M., Gilmiyarova F.N., Domenyuk D.A., DMITRIENKo S.V., IVANYUTA S.O., BUDAYCHIEV

G. M-A. Evaluation of cariogenic situation in children with type 1 diabetes mellitus given the mineralizing potential of saliva and enamel resistance. Kubanskij nauchnyj medicinskij vestnik. 2018; 25(4): 22-36. (In Russ., English abstract). DOI: 10.25207 / 1608-62282018-25-4-22-36.

8. Domenyuk D.A., Zelensky V.A., RZhepakovSKY I.V., ANFINOGENOVa O.I., PUSHKIN S.V. Application of laboratory and $\mathrm{x}$-ray gentral studies un early diagnostics of metabolic disturbances of bone tissue in children with autoimmune diabetes mellitus. Entomology and Applied Science Letters. 2018; 5(4): $1-12$.

9. Domenyuk D.A., Zelensky V.A., DMitrienko S.V., ANFinogenova O.I., Pushkin S.V. Peculiarities of phosphorine calcium exchange in the pathogenesis of dental caries in children with diabetes of the first type. Entomology and Applied Science Letters. 2018; 5(4): 49-64.

10. Domenyuk D.A., Karslieva A.G., BYKov I.M., KochKonyan A.S. Evaluation of cariogenic situation in children with dentoalveolar anomalies based on microbiological and biophysical indicators in oral liquid. Kubanskij nauchnyj medicinskij vestnik. 2014; (5): 36-46. (In Russ., English abstract). DOI: 10.25207/1608-6228-2014-5-36-46.

11. Gilmiyarova F.N., Davydov B.N., Domenyuk D.A., IvCHENKo L.G. Influence of severity of type I diabetes mellitus in children on dental status and immunological, biochemical parameters of blood serum and oral fluid. Part I. Periodontology. 2017; Vol. XXII; 2 (83): 53-60. (In Russ.).

12. Dmitrienko S.V., Domenyuk D.A. Dentoalveolar specifics in children with cleft palate during primary occlusion period. Archiv EuroMedica, 2018; Vol. 8; 1 : 33-34.

13. Davydov B.N., Gilmiyarova F.N., Domenyuk D.A., IvCHENKo L.G. Clinical and diagnostic significance of the activity of matrix metalloproteinase and their tissue inhibitors in assessing the condition of periodontal tissues in children with type 1 diabetes mellitus. Part I. Pediatric Dentistry and Prophylaxis. 2017; Vol. XVI; 4 (63): 14-19. (In Russ.).

14. IVChenko L.G., Domenyuk D.A. Diagnosis of immunometabolic disorders in children with type I diabetes mellitus. Kuban Scientific Medical Bulletin. 2017; 1(2): 73-82. (In Russ., English abstract). DOI:10.25207/1608-6228-2017-2-73-82. 
15. GilmiYarova F.N., Davydov B.N., DomenyUK D.A., IVCHENKo L.G. Influence of severity of type I diabetes mellitus in children on dental status and immunological, biochemical parameters of blood serum and oral fluid. Part II. Periodontology. 2017; Vol. XXII; 3 (84): 36-41. (In Russ.).

16. IVCHENKo L.G., BYKov I.M., BASOv A.A., GilmiYarova F.N., DOMENYUK D.A., BUdAYChIEv G. M-A., Ivanuta S.O. Development and justification of the estimation algorithm of the bone system metabolism in children with type 1 diabetes mellitus. Kubanskij nauchnyj medicinskij vestnik. 2018; 25(5): 35-47. (In Russ., English abstract). DOI: 10.25207/1608-6228-2018-25-5-35-47.

17. Davydov B.N., Gilmiyarova F.N., Domenyuk D.A., IvCHENKo L.G. Clinical and diagnostic significance of the activity of matrix metalloproteinase and their tissue inhibitors in assessing the condition of periodontal tissues in children with type 1 diabetes mellitus. Part II. Pediatric Dentistry and Prophylaxis. 2018; Vol. XVII; 1 (64): 37-46. (In Russ.).

18. Shkarin V., Domenyuk D., Lepilin A., Fomin I., DMITRIENKo S. Odontometric indices fluctuation in people with physiological occlusion. Archiv EuroMedica, 2018; Vol. 8; 1: 12-18.

19. Domenyuk D.A., Lepilin A.V., Fomin I.V., DMITRIENKo S.V. Improving odontometric diagnostics at jaw stone model examination. Archiv EuroMedica, 2018; Vol. 8; 1: 34-35.

20. Domenyuk D.A., Porfyriadis M.P., BudayCHIEV G. M-A. Contemporary methodological approaches to diagnosing bone tissue disturbances in children with type i diabetes. Archiv EuroMedica, 2018; 8(2): 71-81.

21. Borodina V.A., Domenyuk D.A., Veisgeim L.D., DMITRIENKo S.V. Biometry of permanent occlusion dental arches - comparison algorithm for real and design indicators. Archiv EuroMedica, 2018; Vol. 8; 1 : $25-26$.

22. Kulikova N.G., Domenyuk D.A., Zelensky V.A., TKaChenko A.S. Evaluation of the effectiveness of pharmaco-physiotherapeutic treatment of catarrhal gingivitis on the results of the condition of mucosal immunity of oral cavity in women in the postpartum period. Medical Bulletin of the North Caucasus. 2017; Vol. 12; 4: 417-421. (In Russ., English abstract). DOI: 10.14300/mnnc.2017.12117.

23. Domenyuk D.A., Davydov B.N., Gilmiyarova F.N., Porfyriadis M.P., Budaychiev G.M.-A. Optimization of pathogenetic therapy of caries of teeth in children sufficiating first type of diabeted diabetes, taking into account the methodological principles of personalized medicine (Part I). The Dental Institute. 2018; 81(4): 81-83. (In Russ.)

24. Domenyuk D.A., Vedeshina E.G., Dmitrienko S.V., Kalashnikova S.A. Qualitative and quantitative crystallographic evaluation of oral liquid under normal conditions and in dentofacial pathology. Kuban Scientific Medical Bulletin. 2016; (5): 38-47. (In Russ., English abstract). DOI:10.25207/16086228-2016-5-38-47.
25. Gavrilova O.A., Domenyuk D.A. Specific features of oral cavity microbiocenosis in children using non-removable orthodontic appliances. Archiv EuroMedica, 2018; 8(2): 91-92.

26. Porfiriadis M.P., DMitrienko S.V., Domenyuk D.A., Budaichiev G.M.A. Mathematic simulation for upper dental arch in primary teeth occlusion. Archiv EuroMedica, 2018; Vol. 8; 1: 36-37.

27. Domenyuk D.A., Davydov B.N., Zelensky V.A., KarsLIEVA A.G. System analysis of risk factors for developing caries in children with dentoalveolar anomalies. Part I. Pediatric Dentistry and Prophylaxis. 2014; Vol. 13; 3 (50): 40-47. (In Russ.)

28. Domenyuk D.A., DAVydov B.N., Zelensky V.A., KarsLieva A.G. Optimizing the diagnosis of dental caries in patients with dental-anomalies based on the identification of prognostic factors (Part II). Institute of Dentistry. 2014; 4 (65): 60-63. (In Russ.).

29. Domenyuk D.A., Chukov S.Z., Anfinogenova O.I., RZHEPAKOVSKY I.V., IVANYUTA O.O. Application of computer microtomography in the study of morphostructural peculiarities of hard tissues of teeth in early forms of carious lesions. Kuban Scientific Medical Bulletin. 2018; 25(6): 57-67. (In Russ., English abstract). DOI: 10.25207/16086228-2018-256-57-67

30. Domenyuk D.A., Davydov B.N., Vedeshina E.G., DMitrienko S.V. Perfection of diagnostic methods of dentoalveolar anomalies by results of studying functional shifts in the system of oral homeostasis (Part I). The Dental Institute. 2016; 71(2): 74-77. (In Russ.).

31. Domenyuk D.A., Zelensky V.A., Vedeshina E.G., BAzIKov I.A. Study of the spectrum of dental composites biological activity in model experiments in vitro. Medical Bulletin of the North Caucasus. 2016; Vol. 11; 2: 179-183. (In Russ., English abstract). DOI: 10.14300/mnnc.2016.11031.

32. Domenyuk D.A., Gilmiyarova F.N., Vedeshina E.G., IVCHENKo L.G. The diagnostic significance of the clinical functional and immunological studies in assessing the effectiveness of complex therapy of chronic gingivitis (Part I). The Dental Institute. 2017; 74(1): 46-47. (In Russ.).

33. Korobkeev A.A., Domenyuk D.A., Shkarin V.V., DMitrienko S.V., Weisheim L.D., KonNov V.V. Anatomical features of the interdependence of the basic parameters of the dental arches of the upper and lower jaws of man. Medical news of North Caucasus. 2018. - Vol. 13. - № 1-1. - P. 66-69. (In Russ., English abstract). DOI: 10.14300/mnnc.2018.13019

34. Gavrilova O.A., Domenyuk D.A. Microbiological verification for the use of thermoplastics in prosthetic treatment of dentition issues in children. Archiv EuroMedica, 2018; 8(2): 88-90.

35. Domenyuk D.A., Konnov V.V., Pichugina E.N. Anfinogenova O.I., Goncharenko A.N., PushKIN S.V. Microcomputed tomography in qualitative and quantitative evaluation of dental enamel demineralization. Entomology and Applied Science Letters. 2018; 5(4): 72-83. 
36. Davydov B.N., Gilmiyarova F.N., Domenyuk D.A., IVCHENKo L.G. Optimization of diagnostics of type I diabetes in children according to the results of cytomorphological studies of buccal epithelium and processes of oxidative stress in the oral cavity. Pediatric Dentistry and Prophylaxis. 2017; Vol. XVI; 3(62): 9-18. (In Russ.).

37. Lepilin A.V., Fomin I.V., Domenyuk D.A., DMitrienko S.V. Diagnostic value of cephalometric parameters at graphic reproduction of tooth dental arches in primary teeth occlusion. Archiv EuroMedica, 2018; Vol. 8; 1: 37-38.

38. DMitrienko S.V., Davydov B.N., V.V. ShKarin, DoMENYUK D.A. Algorithm for determining the size of artificial teeth by the morphometric parameters of the face in people with full adentia. Dentistry. 2018; 97(6): 57-60.

39. Korobkeev A.A., Domenyuk D.A., ShKarin V.V., Dmitrienko S.V. Types of facial heart depth in physiological occlusion. Medical news of North Caucasus. 2018; Vol. 13; 4: 627-630. (In Russ., English abstract). DOI: 10.14300/mnnc.2018.13122

40. Domenyuk D.A., Karslieva A.G., Bykov I.M., KOCHKONYAN A.S. Evaluation of quantitative parameters of parodontopathogenic and residential microflora in gingival sulcus biofilm in children and adolescents with dentoalveolar anomalies. Kubanskij nauchnyj medicinskij vestnik. 2014; (4): 39-50. (In Russ., English abstract). DOI: 10.25207/1608-62282014-4-39-50.

41. Domenyuk D.A., Gilmiyarova F.N., Vedeshina E.G., IvCHENKo L.G. The diagnostic significance of the clinical functional and immunological studies in assessing the effectiveness of complex therapy of chronic gingivitis (Part II). The Dental Institute. 2017; 75(2): 30-33. (In Russ.).

42. Domenyuk D.A., Zelensky V.A., Karslieva A.G., BAzIKov I.A. Assesment of microbiological status in children with abnormalities of dental system by the results bakteriologis of molecular genetic research. Medical Bulletin of the North Caucasus. 2014; T. 9; 4(36): 344-348. (In Russ., English abstract). DOI: 10.14300/mnnc.2014.09096.

43. Domenyuk D.A., Tashueva L.V., Zelensky V.A., IVANCHEVA E.N. Evaluation of microvasculature tissues viability after the imposition of removable orthodontic appliances in children and adolescents // Archiv EuroMedica, 2013. - Vol. 3. - № 1. - P. 5-9.

44. Karslieva A.G., Domenyuk D.A., Zelensky V.A. Mixed saliva trace element composition in children with dentoalveolar anomalies through apparatusinvolved treatment // Archiv EuroMedica, 2014. Vol. 4. - № 1. - P. 29-35.

45. Domenyuk D., Porfyriadis M., Dmitrienko $S$. Major telerenthengogram indicators in people with various growth types of facial area. Archiv EuroMedica, 2018; Vol. 8; 1: 19-24.

46. Shkarin V.V., Davydov B.N., Domenyuk D.A., DMitrienko S.V. Non-removable arch orthodontic appliances for treating children with congenital maxillofacial pathologies - efficiency evaluation. Archiv EuroMedica, 2018; Vol. 8; 1: 97-98.

47. Davydov B.N., Domenyuk D.A., DMitrienko S.V. Changes of the morphological state of tissue of the paradontal complex in the dynamics of orthodontic transfer of teeth (experimental study). Periodontology. 2018; Vol. XXIII; 1 (86): 69-78. (In Russ.). 